\title{
BMJ Open Public health practicum: a scoping review of current practice in graduate public health education
}

\author{
Hannah Gummeson, Sonika Raj Goel, Khalifa Elmusharaf
}

To cite: Gummeson $\mathrm{H}$, Raj Goel S, Elmusharaf K. Public health practicum: a scoping review of current practice in graduate public health education. BMJ Open 2021;11:e047512. doi:10.1136/ bmjopen-2020-047512

- Prepublication history for this paper is available online. To view these files, please visit the journal online (http://dx.doi. org/10.1136/bmjopen-2020047512).

Received 10 December 2020 Revised 29 March 2021 Accepted 20 April 2021

Check for updates

(C) Author(s) (or their employer(s)) 2021. Re-use permitted under CC BY-NC. No commercial re-use. See rights and permissions. Published by BMJ.

School of Medicine, University of Limerick, Limerick, Ireland

Correspondence to Dr Khalifa Elmusharaf; Khalifa.elmusharaf@ul.ie

\begin{abstract}
Objectives The objectives of this study are to (1) identify Graduate Public Health (GPH) programmes with an integrated practicum, (2) determine current practice for practicum design and (3) use the information to make recommendations to inform the design of Public Health Graduate programme practicums.

Design Scoping review.

Data sources Academic Ranking World Universities 2019 was used to identify top 10 institutions in each geographical hub offering GPH programmes. Each GPH programme website was searched for practicum information.
\end{abstract}

Eligibility criteria GPH programmes offering a practicebased component as a requirement in their curriculum. Data extraction and synthesis One reviewer screened GPH websites for eligibility and extracted data. Verification of data for accuracy and completeness was done on $10 \%$ of the sample by the second author. Data were compiled into an Excel file and were analysed to describe the duration, timing, credit, contact hours, preceptor requirements, prerequisites, objectives, deliverables and methods of evaluation of the practice-based component. Results Out of the $108 \mathrm{GPH}$ programmes screened, a total of 35 programmes were included. There was a significant variation in required practicum duration ranging from 4 to 16 weeks. Only $31 \%$ specifically outlined prerequisites to be completed before the initiation of the practicum. More than half $(57 \%)$ had a published list of core competencies. A majority of practicum did not provide criteria for appropriate preceptors $(63 \%)$ and their responsibilities (66\%). All programmes listed assessment criteria however the majority $(57 \%)$ did not specify if the practicum was graded or a for-credit component.

Conclusions The integration of practical components into curricula is inconsistent. This research resulted in 14 recommendations intended to guide GPH practicum design. We propose that this study be used as a tool to spark a global dialogue about best practices in GPH education through the identification of common practices and opportunities for improvement.

\section{BACKGROUND}

Public health is increasingly moving to the forefront of graduate education within the health sector. As many of the relevant educational entities have begun the slow shift to an integrative approach to care, competency

\section{Strengths and limitations of this study}

The major strength of this review is that it is based on a global sample of graduate public health programmes, allowing for a global perspective on the current practices in Public Health Graduate programme design.

- The information collection was restricted by what was publicly available on programme websites. We acknowledge this as a potential source of bias. Given that the information in the public domain is under the control of the academic programmes and not subject to peer-review, the assumption was made that the details were accurate and up to date.

- Programmes were identified based on the Academic Ranking World Universities. This ranking is based on factors that is related public health research outputs. These factors are not related to the quality of practice-based component as a requirement in their curriculum.

- The sample was limited to programmes offering information available in English which led to the exclusion of institutions in Central and South America.

in public health is now being recognised as critical to success in many healthcare fields as new members enter the workforce.

Over the past 20 years, the model of graduate education in public health has undergone multiple stages of development. Best practices have rapidly diverged from the traditionalist dialectical teaching approach towards one placing more emphasis on student-led learning in competency-based educational models. ${ }^{1}$ As an example, for certain institutions affiliated with the Council on Education for Public Health $(\mathrm{CEPH})^{2}$ or the Public Health Agency of Canada (PHAC), ${ }^{3}$ accreditation is contingent on all Masters of Public Health (MPH) students completing a practicum. Capacity building has been the primary motivation behind these changes.

While relatively new to public health education, the value of experiential learning in education is well described in the literature relating to other allied health fields such 
as medicine, nursing and social work. ${ }^{4-6}$ Akin to these sectors, public health occurs primarily in the field and it has been demonstrated that experiential learning is critical to capacity building in public health education. ${ }^{7-9}$ Practice-based learning puts theory into action, allowing students to work towards competency development through the application of theoretical knowledge to realworld issues. These mentored experiences are also critical to career development, providing unique opportunities to develop professional networks, gain experience in different work-environments and collaborate with others in the field of public health. ${ }^{10}$ This model builds on the traditional research-focused thesis paradigm towards one of implementation science, where the new generation of public health practitioners are supported to develop interdisciplinary skills for multisector engagement to move from research to action. ${ }^{911}$

The growing integration of practice-based learning into graduate public health $(\mathrm{GPH})$ curricula signals a divergence from the traditional education model. Many GPH institutions are beginning to capitalise on this by offering programmes with the option of a thesis-based or practice-based culminating project. That being said, there is significant variation in the method of integrating an experience-based component into the curriculum. Multiple different terms are used including practicum, internship, applied practical experience (APE), culminating experience, field placement, residency and professional placement, to name a few. There is meaningful diversity here. However, practicum-based programmes are still not the norm, especially in Europe. This is evidenced by the vast majority of globally ranked institutions in the region continuing to offer only thesis-based programmes, with no practice-based element required. While this approach may have once served a research-driven culture of healthcare, the future of public health education lies in practice to action.

When considering the design of public health programmes going forward, we hoped to answer the research question 'what are the current best practices in GPH education?' The objectives of this review are to (1) identify leading GPH programmes with an integrated practicum, (2) determine current practice for practicum design through a global lens and (3) use the information to make recommendations to inform the design of public health graduate programme practicum.

\section{METHODS}

This scoping review of GPH programmes was conducted by adopting a methodological framework first described by Arksey and O'Malley ${ }^{12}$ and later refined by Levac $e t$ $a l .{ }^{13}$ As our inquiries were focused primarily on 'grey literature, we chose this methodology given that research indicates it is particularly useful for 'reconnaissance' into subject matter that has not yet been comprehensively reviewed. ${ }^{14-16}$ The steps include (1) identifying research questions, (2) identifying all relevant programmes, (3) selecting significant programmes, (4) charting the relevant data and then (5) summarising and reporting the results. A Preferred Reporting Items for Systematic Reviews and Meta-Analyses for Scoping Reviews (PRISMA-ScR) checklist report was completed to ensure all measures were achieved.

\section{Purpose}

The purpose of the research is to review the structure of GPH practicums using a globally diverse sample to identify common themes and inform current practice for practicum design moving forward.

\section{Search strategy}

Data collection for this research was entirely web based. As described in more detail below, potential programmes were identified using online university ranking systems and were then stratified by geographical region into ranked lists. To be included in the sample, GPH programmes must incorporate a practice-based component into the curriculum. In some instances, the regionally top 10 ranked GPH programmes did not include a practice-based component. As such, the goal was to create a sample representing the top five practice-based GPH programmes in each of the regions identified.

\section{Identifying relevant programs}

The goal in data collection was to create a globally descriptive sample of GPH programmes offering a practice-based component as a requirement in their curriculum. Top-ranked GPH programmes were divided based on continental hubs to ensure a geographically diverse sample. The hubs included were Africa, Asia, Australia, Canada, European Union, South America, UK and the USA. Examination of databases created by World University Ranking 2019 (WUR) and Academic Ranking World Universities 2019 (AWRU) identified the top 10 (ranked) institutions in each geographical hub offering GPH programmes. It should be noted that initial database queries were done using both WUR and AWRU. However, WUR ranking focused at the university level as compared with AWRU, which ranked the GPH programmes themselves as opposed to the university as a whole. Due to the specificity of the search parameters, we chose to focus our search on the AWRU system, although there was significant overlap between the two algorithms. AWRU methodology of subject ranking is mainly based on public health research outputs rather than the components of the programme or the curriculum. To be included in the public health subject ranking, the universities need to have a minimum of 200 publications during the period of 2014-2018. Universities are then ranked based on five indicators: (1) Q1 is the number of papers published in Q1 Journal Impact Factor Quartile, (2) Category Normalised Citation Impact, (3) Publications with International collaboration, (4) The number of papers published in Top Journals and (5) The number of the staff wining a significant award. 


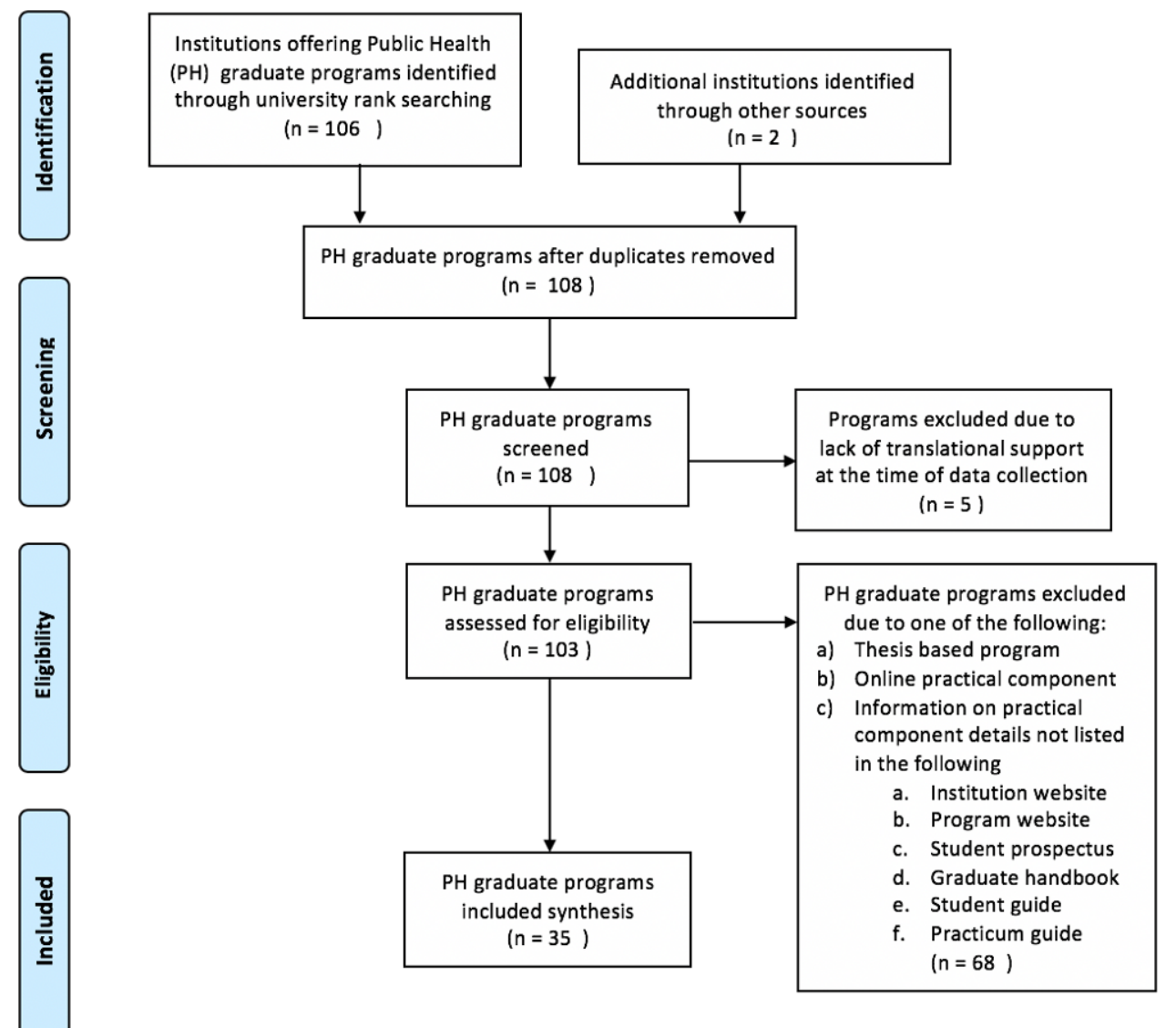

Figure 1 PRISMA-ScR flow diagram outlining the process of public health programme selection for the sample. The PRISMAScR diagram details our search and selection process applied during the research. PRISMA-ScR, Preferred Reporting Items for Systematic Reviews and Meta-Analyses extension for Scoping Reviews.

\section{Selecting the programmes for inclusion (eligibility criteria)}

Phase two screening and subsequent data collection was based on global AWRU GPH programme rankings for each respective geographical region. The AWRU was used as a framework to systematically assess the programmes offered, starting with the highest-ranking region. Any of the top-ranked GPH programmes not requiring a practicebased component in the curriculum were excluded from the sample. Programmes were also excluded if a practicebased component was mentioned but the information was unavailable through (1) university website, (2) programme website, (3) student prospectus, (4) graduate handbook, (5) student guide or (6) practicum guide. Search parameters are outlined in a PRISMA-ScR chart (figure 1).

\section{Information sources}

The university website, programme website, student prospectus, graduate handbook, student guide and practicum guide of each selected university were searched for available information about the practicebased component.

\section{Search}

The following keywords were used for the search: Practicum, workplace practicum, APE, internship, practice internship, residency, placement, professional placement, project in public health, pathways to public health in the workplace, community placement, professional practice, professional project, field study or field work.

\section{Data charting process}

Information about the programme and the practicebased component was downloaded and stored in a series of electronic files. To collect data systematically, an electronic abstraction proforma was created in Excel. Information on each practice-based component was reviewed and the data was entered into a master file comparing all the selected institutions based on domains of interest. The lead author was mainly responsible for screening the programmes using the inclusion and exclusion criteria. The second author performed verification of data for accuracy and completeness on $10 \%$ of the sample. All the coauthors had meetings at regular intervals during the review process to discuss the emerging results, and to resolve any issues arising in the search process.

\section{Sample}

We screened 108 GPH programmes. Our search strategy yielded $40 \mathrm{GPH}$ programmes representing all continents across the globe. Due to lack of translation support at the time of data collection, 5 schools in Chile, Brazil, 
Mexico and Puerto Rico were excluded, leaving $35 \mathrm{GPH}$ programmes in the sample.

\section{Data items}

Data were collected on the duration, timing, credit and contact hours of the programme practice-based component, as well as data on preceptor requirements, prerequisites, objectives, deliverables and methods of evaluation of the practice-based component. This study was considered exempt from institutional ethical board review as it did not involve human subjects.

\section{Synthesis of results}

Data were compiled from available online sources and collated into an Excel file. Descriptive statistics were computed for each study variable and are presented in the following section.

\section{Patient and public involvement}

Patients or the public were not involved in the design, or conduct, or reporting, or dissemination plans of our research.

\section{RESULTS}

\section{Characteristics of Public health programmes reviewed}

Data were collected on the duration, timing, credit and contact hours of the programme practice-based component, as well as data on preceptor requirements, prerequisites, objectives, deliverables and methods of evaluation of the practice-based component.

As seen in table 1, the programmes included in the sample compose a snapshot of a variety of accrediting bodies that GPH programmes may affiliate with. Of the sample institutions with accredited programmes, the majority $(n=6)$ received accreditation through $\mathrm{CEPH}$, while others maintain accreditation through Agency for Public Health Education Accreditation (APHEA) $(n=3)$, Netherlands Flemish Accreditation Organisation ( $n=2)$ as well as International Union for Health Promotion and Education, Training Programme in Epidemiology and Public Health Interventions Network and several national ministries of education (collective $n=4$ ). The majority of the programmes were not accredited $(n=20,57 \%)$. In terms of overall programme structure, programme duration followed a bimodal distribution, with $34 \%$ of programmes requiring a minimum of 12 months for completion and $66 \%$ requiring $13-24$ months.

\section{Structural characteristics of GPH practicums}

Prerequisites and practicum scheduling

Approximately one-third of the programmes evaluated $(\mathrm{n}=11,31 \%)$ specifically outlined prerequisites to be completed before the initiation of the practicum. The remainder of the programmes $(n=24,69 \%)$ did not list prerequisites in any of the available course information. However, some of these schools may have accounted for that omission through the practicum schedule. The majority of programmes $(n=24,68 \%)$ stipulated that the
Table 1 Characteristics of universities reviewed $(n=35)$

\begin{tabular}{lll}
\hline Characteristic & No & Percentage \\
\hline $\begin{array}{l}\text { Geographical region } \\
\text { Africa }\end{array}$ & 5 & 14 \\
\hline Asia & 5 & 14 \\
\hline Australia & 5 & 14 \\
\hline Canada & 5 & 14 \\
\hline European Union & 5 & 14 \\
\hline UK & 5 & 14 \\
\hline USA & 5 & 14 \\
\hline $\begin{array}{l}\text { Accrediting body } \\
\text { Council on Education for Public }\end{array}$ & 6 & 17 \\
\hline Health & 1 & 2.75 \\
\hline $\begin{array}{l}\text { Training Programme in } \\
\text { Epidemiology and Public Health } \\
\text { Interventions Network }\end{array}$ & & \\
\hline $\begin{array}{l}\text { International Union for Health } \\
\text { Promotion }\end{array}$ & 1 & 2.75 \\
\hline $\begin{array}{l}\text { Agency for Public Health } \\
\text { Education Accreditation }\end{array}$ & 3 & 9 \\
\hline $\begin{array}{l}\text { Netherlands Flemish Accreditation } \\
\text { Organisation }\end{array}$ & 2 & 6 \\
\hline $\begin{array}{l}\text { Ministry of education } \\
\text { No accrediting body }\end{array}$ & 2 & 6 \\
\hline $\begin{array}{l}\text { Programme duration } \\
\text { 12 months or less }\end{array}$ & 20 & 57 \\
\hline \begin{tabular}{l}
$13-24$ months \\
\hline
\end{tabular} & 12 & 34 \\
\hline
\end{tabular}

practicum could only take place after a minimum of two terms were completed (ie, summer semester in 12-month programmes, semester three or four in 16-24 months programmes).

\section{Practicum contact hours and duration}

As seen in table 2, there was significant variation in required practicum duration with a range measured both in hours or weeks depending on the institution. For placements measured in hours, two $(6 \%)$ of the practicums were in the range of $50-100$ hours, four (11\%) were in the range of 101-200 and one (3\%) was in the range of 201 or more hours. For placements measured in weeks, three $(9 \%)$ were between 4 and 8 weeks, nine $(26 \%)$ were between 9 and 12 weeks and $6(17 \%)$ were between 13 and 16 weeks. Ten $(28 \%)$ of the practicums did not have a defined time requirement.

In terms of contact hours, a significant portion of the institutions reviewed $(49 \%)$ did not specify the number of contact hours to be completed within a set duration placement duration measured in weeks. Additionally, over a quarter of programmes $(28 \%)$ did not specify a required contact time at all. Of those that did specify a finite number of contact hours (23\%), six stated only the minimum number of contact hours required whereas the 
Table 2 Structural characteristics of GPH practicums reviewed $(n=35)$

\begin{tabular}{|c|c|c|}
\hline Characteristic & No & Percentage \\
\hline \multicolumn{3}{|c|}{ Prerequisites required before practicum initiation } \\
\hline Prerequisite courses required & 11 & 31 \\
\hline Prerequisite courses not listed & 24 & 69 \\
\hline \multicolumn{3}{|l|}{ Timing of practicum scheduling } \\
\hline Semester 2 & 3 & 9 \\
\hline Semester 3/summer & 13 & 37 \\
\hline Year 2 & 11 & 31 \\
\hline Variable term/undefined & 8 & 23 \\
\hline \multicolumn{3}{|l|}{ Practicum duration } \\
\hline $50-100$ hours & 2 & 6 \\
\hline $101-200$ hours & 4 & 11 \\
\hline 201 or more hours & 1 & 3 \\
\hline 4-8 weeks & 6 & 17 \\
\hline $9-12$ weeks & 9 & 26 \\
\hline 13-16 weeks & 6 & 17 \\
\hline Practicum duration not defined & 10 & 28 \\
\hline \multicolumn{3}{|l|}{ Contact hours } \\
\hline $\begin{array}{l}\text { Stated minimum number contact } \\
\text { hours only }\end{array}$ & 6 & 17 \\
\hline $\begin{array}{l}\text { Stated minimum and maximum } \\
\text { number contact hours }\end{array}$ & 2 & 6 \\
\hline Contact time measured in weeks & 17 & 49 \\
\hline Contact time not specified & 10 & 28 \\
\hline
\end{tabular}

\section{Credit hours}

$\begin{array}{lrr}\text { No credit hours for practicum } & 1 & 3 \\ \begin{array}{l}\text { Fixed number of credit hours for } \\ \text { practicum }\end{array} & 32 & 91 \\ \begin{array}{l}\text { Practicum credit hours not } \\ \text { provided }\end{array} & 2 & 6\end{array}$

Ratio of credits to overall degree

\begin{tabular}{lrr} 
No credit hours for practicum & 1 & 3 \\
\hline $1 \%-10 \%$ overall credits & 8 & 22 \\
$11 \%-20 \%$ overall credits & 15 & 43 \\
$21 \%-30 \%$ overall credits & 3 & 9 \\
$31 \%-40 \%$ overall credits & 5 & 14 \\
\hline Information unavailable & 3 & 9 \\
\hline
\end{tabular}

GPH, Graduate Public Health.

other two gave both the minimum and maximum hours required.

\section{Credit hours and overall credit weighting}

As seen in table 2, one, (3\%) of the practicums reviewed did not earn any credit hours and two $(6 \%)$ programmes did not provide a credit-hour equivalency for the practical component in the course information. The vast majority $(91 \%)$ of practicums reviewed had a fixed number of credit hours associated. The units of measurement of the credit hours were varied but included credits, credit hours, weighted marks and European Credit Transfer System credits.

\section{GPH practicum domains}

In addition to analysing the operational elements of practicum design, data collection also focused on core domains including (1) competencies, (2) supervision, (3) written agreement and objectives and (4) assessment.

\section{Competencies}

As seen in table 3, more than half $(n=20,57 \%)$ of the GPH programmes reviewed had a published list of core programme competencies. The competencies associated with programmes offered by the North American institutions are derived from national standards developed by CEPH and PHAC. In other centres, core competencies were institution specific. The remainder of the sample $(\mathrm{n}=15,43 \%)$ did not list programme competencies.

In addition to programme-centred competencies, several centres also defined practicum-specific competencies. Eight (23\%) of the practicums had clearly listed competencies that guided the development of the practicum deliverables and one $(3 \%)$ referenced practicum-specific competencies without further definition of their content. However, for the majority of practicums $(74 \%)$, no practicum specific was included in any of the course guidelines available. It is unclear if these programmes had not developed practicum-specific competencies or if they were not listed in the available programme documentation.

\section{Supervision}

As seen in table 3 , institutional oversight into practicum supervisors occurred at several levels, both through the definition of eligibility criteria and supervisory responsibilities. Approximately one-third $(37 \%)$ of practicums had stated criteria used to define appropriate preceptors as outlined in table 4, whereas the majority $(67 \%)$ did not provide criteria or the information was not listed. A similar proportion of programmes $(34 \%)$ clearly stated the responsibilities of the supervising preceptors, but the majority $(66 \%)$ did not.

\section{Written agreement, objectives and deliverables}

Over one-third (40\%) of the programmes required a written agreement to be in place before the student could begin working on the practicum. This was a universal requirement in the North American programmes $(n=10)$, however, approximately two-thirds of programmes in the sample $(60 \%)$ did not reference any form of written agreement as a requirement for the practicum. In terms of practicum objectives, the majority of programmes provided a defined list (83\%), however, only one-third $(34 \%)$ of institutions reviewed contracted these objectives into a learning agreement. All of the practicum written agreements outline some specific deliverables to be completed and used as part of the assessment metric. The 
Table 3 Domains of GPH practicums reviewed $(n=35)$

\begin{tabular}{|c|c|c|}
\hline Domain & No & Percentage \\
\hline \multicolumn{3}{|l|}{ Competencies } \\
\hline \multicolumn{3}{|l|}{ Core competencies } \\
\hline $\begin{array}{l}\text { Core public health } \\
\text { competencies listed }\end{array}$ & 20 & 57 \\
\hline $\begin{array}{l}\text { Core public health } \\
\text { competencies not listed }\end{array}$ & 15 & 43 \\
\hline \multicolumn{3}{|c|}{ Practicum-specific competencies } \\
\hline $\begin{array}{l}\text { Practicum-specific } \\
\text { competencies defined }\end{array}$ & 8 & 23 \\
\hline $\begin{array}{l}\text { Practicum-specific } \\
\text { competencies referenced, } \\
\text { undefined }\end{array}$ & 1 & 3 \\
\hline $\begin{array}{l}\text { Practicum-specific } \\
\text { competencies not listed/ } \\
\text { missing }\end{array}$ & 26 & 74 \\
\hline
\end{tabular}

\section{Supervision}

Practicum supervisor criteria

$\begin{array}{lcc}\begin{array}{l}\text { Stated criteria to define } \\ \text { appropriate supervisor }\end{array} & 13 & 37 \\ \begin{array}{l}\text { No criteria listed to define } \\ \text { appropriate supervisor }\end{array} & 23 & 63 \\ \begin{array}{l}\text { Practicum supervisor responsibilities } \\ \begin{array}{l}\text { Stated responsibilities of } \\ \text { practicum supervisor }\end{array}\end{array} & 12 & 34 \\ \begin{array}{l}\text { Did not state responsibilities of } \\ \text { practicum supervisor }\end{array} & 66\end{array}$

\section{Written agreement and objectives}

Written agreement

$\begin{array}{lll}\text { Written agreement required } & 14 & 40 \\ \begin{array}{l}\text { Written agreement not } \\ \text { referenced }\end{array} & 21 & 60\end{array}$

Practicum objectives

$\begin{array}{lcc}\begin{array}{l}\text { Objectives included in the } \\ \text { written agreement }\end{array} & 12 & 34 \\ \begin{array}{l}\text { Objectives not included/ } \\ \text { unclear if in written agreement }\end{array} & 2 & 6 \\ \begin{array}{l}\text { Practicum objectives defined } \\ \text { Practive }\end{array} & 83\end{array}$

Final deliverables (multiple per programme)

\begin{tabular}{lrr}
\hline No requirement & 0 & 0 \\
\hline Oral presentation & 13 & 37 \\
\hline Written report & 17 & 49 \\
\hline Portfolio/reflections & 3 & 8 \\
\hline Poster/abstract & 5 & 14 \\
\hline $\begin{array}{l}\text { Practicum-specific deliverables } \\
\text { Not listed/unclear requirement }\end{array}$ & 6 & 46 \\
\hline $\begin{array}{l}\text { Assessment } \\
\text { Assessment Intervals }\end{array}$ & 17 \\
$\begin{array}{l}\text { Pre-practicum (learning } \\
\text { agreement) }\end{array}$ & 14 & 40 \\
\hline
\end{tabular}

Continued

\begin{tabular}{lrl}
\hline Table 3 Continued & & \\
\hline Domain & No & Percentage \\
\hline Mid-practicum & 9 & 26 \\
Postpracticum & 21 & 60 \\
$\begin{array}{l}\text { Assessment information not } \\
\text { available }\end{array}$ & 9 & 26 \\
$\begin{array}{l}\text { Final grading system } \\
\quad \text { Pass/fail }\end{array}$ & \\
$\quad$ Letter grade & 8 & 23 \\
$\quad$ No grade/unclear & 7 & 20 \\
\hline
\end{tabular}

GPH, Graduate Public Health.

majority $(83 \%)$ required students to submit or present a product at the completion of the practicum. Of all 35 practicums reviewed, $6(17 \%)$ had no stated final deliverables, $3(8 \%)$ required a portfolio or reflection, $5(14 \%)$ required a poster or abstract, $13(37 \%)$ required an oral presentation, $16(46 \%)$ required 'practicum-specific deliverables' and $17(49 \%)$ required a written report. It should be noted that one practicum may have had a combination of multiple deliverables required.

\section{Approach to assessment}

As seen in table 3, of those practicums which listed the grading information, eight $(23 \%)$ were graded on a pass/fail basis and seven (20\%) were evaluated using a letter grade system. All programmes listed assessment criteria, however, the majority in this sample $(57 \%)$ did not provide specify if the practicum was graded or a forcredit component. The majority of the practicums $(74 \%)$ had defined assessment intervals with $40 \%$ requiring a preplacement assessment, that is, learning agreement, $26 \%$ requiring an interim assessment and $60 \%$ requiring

\begin{tabular}{|c|c|c|}
\hline Criteria defined & No & Percentage \\
\hline Expertise in project area & 5 & 38 \\
\hline $\begin{array}{l}\text { Experience and status within the } \\
\text { organisation }\end{array}$ & 5 & 38 \\
\hline $\begin{array}{l}\text { Interest and competence in } \\
\text { supervising and mentoring }\end{array}$ & 5 & 38 \\
\hline Professional credentialing & 8 & 62 \\
\hline $\begin{array}{l}3-5 \text { years experience with } \\
\text { advanced master or doctoral } \\
\text { degree }\end{array}$ & 1 & 8 \\
\hline $\begin{array}{l}10 \text { years experience with bachelor } \\
\text { degree or equivalent combination } \\
\text { of education and experience }\end{array}$ & 4 & 30 \\
\hline $\begin{array}{l}\text { MPH or master degree in the } \\
\text { related field }\end{array}$ & 1 & 8 \\
\hline
\end{tabular}

MPH, Masters of Public Health. 
Table 5 Descriptive terminology for practical placements $(n=35)$

\begin{tabular}{lcc}
\hline Terms used & No & Percentage \\
\hline Practicum/workplace practicum & 14 & 40 \\
Applied practical experience & 2 & 6 \\
Internship/practice internship & 7 & 20 \\
Residency & 2 & 6 \\
Placement/professional placement & 3 & 8 \\
Project in public health & 1 & 2.75 \\
Pathways to public health in the & 1 & 2.75 \\
workplace & & \\
Community placement module & 1 & 2.75 \\
Professional practice & 1 & 2.75 \\
Professional project & 1 & 2.75 \\
Field study/work & 2 & 6 \\
\hline
\end{tabular}

a postplacement assessment. Assessment information was not available for nine $(26 \%)$ programmes.

\section{Definitions and terminology}

As seen in table 5, the language used to describe the 'practicum' component was quite diverse across all the GPH programmes assessed. The term practicum or workplace practicum was most common $(40 \%)$, the internship was the next most common term (20\%) and placement was also used by several programmes (8\%). Other less commonly used terms include Applied practical experience, residency, professional practice or project and field work.

\section{DISCUSSION}

When considering the design of public health programmes going forward, it is important to review recent developments to establish current best-practice in GPH education.

\section{Challenges}

Practical placements are extremely beneficial to students, ${ }^{10} 17$ as evidenced by their integration into many of the leading public health masters' programmes worldwide. However, this review demonstrated significant variation in practicum design, use of guidelines, and accreditation between the programmes reviewed. Overall, there were several interesting trends identified in the data that warrant further discussion.

\section{Practicum design}

Many of the programmes included in this review in Europe were thesis based. These programmes have not yet progressed to incorporate a mandatory practice requirement into their education model when the evidence indicates the many benefits of practicums.

Although practicums are becoming more ubiquitous in GPH education, there is significant variation in the methods by which academic institutions integrate a practice-based component into their MPH programmes. In the North American, context design is highly regulated, where CEPH and PHAC have issued explicit guidelines that dictate the design of GPH practicums. However, the public health community has yet to develop a clearly defined and globally accepted set of guidelines outlining a superior practicum scheme that gives students better experience and prepare them for their career, in addition to meeting the needs of the communities being served and the people they intend to educate. In this way, practicums are being used as a response to the need for social accountability in health professional education. ${ }^{18} 19$ While this variation poses a logistic challenge to implementing quality measures in public health education, it also emphasises the need to integrate flexibility into programme design to ensure the needs of both students and communities served are being met.

A current example of emerging innovation in GPH practice-based education is the virtual practicum. It has been suggested as a pioneering solution to meet the needs of GPH students in distance learning programmes or those who are pursuing a GPH in parallel with an existing career. ${ }^{20}$ In the era of COVID-19, we anticipate programmes will face increasing challenges with in-person practicum placements and that exploration of virtual or blended practicum models should be prioritised. While the virtual practicum design is not yet widely integrated into GPH practicums on a global scale, it is reasonable to anticipate that this approach will become more commonplace in years to come.

\section{Practicum design guidelines}

Another finding of note relates to the global variation in guidelines for practicum design. Some institutions are operating off a national standard that defines the required elements of a practice-based experience, ${ }^{23}$ but many are not. Likely, the diversity of 'practicum types' encountered in this review is due in large part to the regional variation in design standards. For example, institutions in North America follow clear guidelines set out by CEPH and PHAC and GPH programmes. Institutions in India follow a national set of recommendations that inform practicum design. Conversely, the majority of programmes in other settings seem to rely on community needs or working group recommendations to guide the practicum design. Based on our review, it is unclear if creating an 'international standard' is feasible as there is such diversity in educational needs.

\section{Accreditation}

Accreditation often provides a clear set of guidelines defining the expectations for programme design. There are multiple accrediting bodies, some being public health institutions and others general education institutions, operating both at national and international levels. It is reasonable to infer that institutions being accredited by public health bodies have programmes that are 
Table 6 Relationship between competencies, objectives and deliverables in practicum design

Competencies Competencies are the central knowledge, skills and attitudes necessary for the public health workforce to practice effectively and achieve the core functions of public healthcare. Competencies define aptitudes or educational outcomes students must acquire on completion of a GPH programme.

\begin{tabular}{ll} 
Objectives & $\begin{array}{l}\text { Objectives are actionable goals developed } \\
\text { by the student in conjunction with the } \\
\text { onsite practicum supervisor and university- } \\
\text { based practicum coordinator. Objective } \\
\text { development is based on educational } \\
\text { outcomes defined by the programme's core } \\
\text { competencies. }\end{array}$ \\
Deliverables $\quad \begin{array}{l}\text { Deliverables are tangible work products } \\
\text { created by the student during the } \\
\text { practicum. Deliverables are informed by } \\
\text { objectives that are developed based on } \\
\text { competencies. }\end{array}$ \\
\hline
\end{tabular}

GPH, Graduate Public Health.

more specifically tailored to the needs of public health education as opposed to those that are not. However, the majority of programmes reviewed were not accredited. This variation in accreditation status raises the question of the necessity of guiding principles in practicum design. Perhaps an interesting example to consider is the Canadian context. In Canada, the majority of programmes are not accredited however they are required to meet the MPH practicum guidelines as defined by PHAC. This effectively has the same outcome as following criteria set by an accrediting body. Currently, it is unclear if universal accreditation would be useful for GPH programmes given the profile of the diverse needs of the global community.

\section{Current practice}

Our comprehensive review of GPH practicum designs around the world have informed the development of an initial framework of recommendations based on current best practices (table 6). The following discussion will focus on the elements identified as critical when considering the design of a GPH practicum.

\section{Learning contract}

The learning contract (LC) is a crucial element to the success of a practicum. The LC is a memorandum of understanding between the student, academic institution and host institution that defines the objectives, expectations and deliverables necessary for successful completion of the placement. ${ }^{21}$ Practicums are often structured differently, as we have seen in our sample and there can be significant variation in the objectives defined and competencies assessed. Nonetheless, a well-designed LC is a key to the success of any practicum. The goal is to translate required competencies into specific objectives that will result in deliverables the student will be able to produce during their practical placement. Well-defined, specific practicum guidelines and objectives should be developed internally, based on competencies established by the university and any relevant accrediting body. Agreement on objectives is essential, not only for the students but also host institutions, to ensure the practicum is beneficial to all parties involved. ${ }^{22}$ In addition, the roles and responsibilities of each partner must be clearly delineated in the LC. This includes a specific agreement about honoraria, data ownership, research products and authorship of publications.

\section{Prerequisite competency training}

GPH programmes should communicate the requirements to students to be prepared to undertake a practicum. We found that some programmes clearly state the prerequisites, while in others it is inherent in the programme schedule. This was a point of interest identified in our review. It highlights the institutional assumptions being made regarding the ethical competence of students. While many programmes emphasise prerequisites that focus on epidemiology and biostatistical analysis, there is little emphasis on the need for ethics training in practicum-based programmes. This is in contrast to thesisbased programmes which consistently integrate the need for ethical approval of research projects into the project authorisation process. There is also a need for training on professionalism, business etiquette and workplace savvy as a prerequisite competency training.

\section{Competency-based training}

Institutions must define the public health competencies that their graduates will attain following programme completion. Some programmes reviewed define key competencies based on frameworks created by an accrediting body such as CEPH, PHAC or APHEA, ${ }^{2} 323$ while others developed competencies based on internal standards. It should be noted that while the specific competencies assessed varied, there were consistent themes between accredited and non-accredited institutions. Once competencies are outlined by the institution, best practice is to create practicum objectives. Objectives are actionable goals developed by the student in conjunction with the onsite practicum supervisor and university-based practicum coordinator. Objectives can then be used to inform the development of specific practicum deliverables, that is, what the student will achieve during the practicum placement (table 6). The current best practice is consistent with the literature in requiring that deliverables are (1) of use to the host institution and (2) meet the criteria determined by the competency-based practicum objectives. ${ }^{24}$ While competency acquisition can be difficult to assess, the LC is a key tool that can be used to measure a student's competency development throughout the programme and practicum. 


\section{Practicum supervisor requirements}

The definition of supervisor requirements is another area that must be addressed in the design of a new GPH practicum. A clear definition is essential to ensure that practicum supervisors (1) are qualified to supervise, (2) have the skill set necessary to be a public health mentor and (3) have the capacity to evaluate students' competency attainment. Many of the institutions reviewed reference the need for a preceptor, and some outline specific qualifications necessary. However, the challenge in this area is that qualifications may be highly practicum specific, with extensive variation in qualifications between medicine, epidemiology, community intervention and programme evaluation. For this reason, many programmes have very vague supervisor requirements, stating that preceptors must be 'experts in their field'. It is clear that supervisors must be qualified and that the requirements must be well defined such that a potential supervisor can be made aware of the expectations around their role in guiding the student through the practicum process. We recommend that institutions define supervisor requirements in a general sense, as seen in many of the North American centres reviewed. In this way, centres allow for variation in supervisor experience while ensuring that each is qualified to provide project-specific support/oversight to a student in the field.

\section{Effective mentorship and evaluation}

Open communication and continuous student feedback are critical to the success of practical placements. This emphasises the importance of the role of the practicum supervisor and the need for continuous assessment. ${ }^{25} 26$ The supervisor plays a dual role in the practicum, both as a mentor and evaluator. ${ }^{27}$ It is the responsibility of the supervisor to work with the student to ensure that they are operating within the scope of their LC and can complete any stated deliverables within the time frame agreed. We recommend conducting periodic evaluations of the students and the placement to assess if the practicum is an appropriate tool to facilitate competency building as required by the programme. ${ }^{28}$ Besides, as the evaluations must be tailored to fit the design of the practicum, it is recommended that both short and long-term assessments are completed from multiple perspectives. While evaluation of student performance is essential to competency development, it is equally important that students are able to assess their supervisors and remain in contact with their home school throughout the practicum should they need support. This emphasises the importance of the role played by the practicum coordinator. The coordinator is a designated faculty member whose role, among other things, is to ensure the lines of communication between student and institution remain open for the duration of the practicum. Based on our review, the use of periodic evaluation is commonplace in current practicum designs. Also, many programmes reviewed required assessments to be carried out by key stakeholders (students, supervisors, host organisation) at mid and final term. These assessments should evaluate both the placement and the student performance.

\section{Strengths and limitations of this study}

The major strength of this review is that it is based on a global sample of GPH programmes, allowing for a global perspective on the current practice in public health graduate programme design. As this has not been done before, this work may serve as an initial foray into the evaluation of global trends in the GPH educational approach. The information gathered has been used to design a proposed set of recommendations to guide future practice. This review can also be used to identify areas in GPH programme design that could benefit from further evaluation.

There were several limitations in this review. Foremost among them, information collection was restricted by what was publicly available on programme websites. We acknowledge this as a potential source of bias. Given that the information in the public domain is under the control of the academic programmes and not subject to peer-review, the assumption was made that the details were accurate and up to date. Besides, programmes were identified based on world ranking systems. While these systems operate off specific methodologies, it is likely discrepancies exist between the assessment algorithms which could easily lead to incompletely representative sampling. Furthermore, only the highest-ranked five programmes with practicum component from each hub were included. This implies that only top-ranked programmes have best practices which may not be the case. In addition, the sample was limited to programmes offering information available in English which led to the exclusion of institutions in Central and South America.

\section{CONCLUSIONS AND RECOMMENDATIONS}

In 2008, Cashman and Seifer ${ }^{29}$ described practice based or experiential learning as 'an effective and appropriate vehicle for teaching public health and developing public health literacy'. After over a decade of development in public health education, this was an opportunity to revisit the statements made in 2008 and reflect on the degree to which we have to be able to align public health education with competency building through practice. The goal in undertaking this review was to develop a deeper understanding of the current practice in GPH programme design, relating to the structure of the practice-based component.

This analysis offers a description of current global best practices in practicum design for GPH education. We have shown that there is meaningful variation in the approach to GPH practicum design, with a significant proportion of the leading public health education centres across the world emphasising the practical elements of training. This speaks to the growing value of practice-based training in the global public health community. 
Currently, there are no global criteria that define the key elements necessary to guide the design of successful GPH practicums. While variation is expected given the different needs profiles seen in a global context, we feel that a general set of guidelines could be beneficial to ensure programmes are all meeting a high educational standard.

Based on our review of current best practice, we have developed a set of fourteen recommendations intended to guide the development and design of GPH programme practicums:

\section{Design}

1. Develop clear practicum prerequisites in order to ensure students are equipped with sufficient ethical and theoretical background knowledge to complete a practicum placement.

2. Schedule the practicum after the completion of practicum prerequisites, that is, second term.

3. Develop a learning contract, that is, a memorandum of understanding between the student, academic and host institutions that define the objectives, expectations and deliverables.

4. Develop a comprehensive practicum handbook.

5. Develop a flexible format that is adaptable to both student and community need with an opportunity to integrate virtual, home-based, e-practicum and in-person elements.

\section{Mentorship and supervision}

6. Define clearly the required qualifications or experience for practicum supervisors.

7. Outline clearly the responsibilities of practicum supervisors and coordinators.

\section{Learning outcomes}

8. List and define the Public health competencies. Competencies describe the essential knowledge, skills and attitudes necessary to practice public health. This may be in alignment with those competencies defined by an accrediting body.

9. Use competencies to create practicum objectives or learning outcomes which are actionable goals developed in collaboration with student, supervisor and coordinator.

10. Use objectives to inform the development of practicum-specific deliverables, that is, what the student will achieve during the placement.

11. Deliverables must be (A) of use to the host institution and (B) meet the criteria determined by competencybased practicum objectives.

\section{Evaluation}

12. Practicum placements should be assessed on a 'for credit' basis.

13. Learning contracts, supervisor evaluations and final reflective reports are used as a metric to determine if the student has completed the deliverables to a professional standard and as agreed.
14. The final assessment is a collaborative effort between the practicum supervisor and coordinator.

The evidence is there supporting the utility of practicebased education and we would recommend that the public health education community continue to shift towards the integration of practice-based experiences into GPH programmes worldwide.

\section{Twitter Khalifa Elmusharaf @elmusharaf1}

Contributors KE conceived the basic idea for the research and supervise the research process. $\mathrm{HG}$ conducted early scoping searches, returning to KE and SRG at intervals for advice. $\mathrm{HG}$ developed a detailed plan for the conduct of comprehensive searches. Any difficulties with the search process arising were discussed with KE at regular intervals. SRG verified data for accuracy and completeness. HG summarised all data found and presented it to KE and SRG for comment and feedback. HG, SRG and KE have made substantial contributions to conception, design, drafting the manuscript and revising it critically for important intellectual content. All the authors have read and approved the final manuscript.

Funding No external funding was applied for or used in the conduct of this research. The School of Medicine at the University of Limerick funded this article.

Disclaimer The funder had no role in construction, evaluation, manuscript preparation, or decision for publication.

Competing interests None declared.

Patient and public involvement Patients and/or the public were not involved in the design, or conduct, or reporting, or dissemination plans of this research.

Patient consent for publication Not required.

Provenance and peer review Not commissioned; externally peer reviewed.

Data availability statement All data relevant to the study are included in the article. All data generated or analysed during this study are included in this published article.

Open access This is an open access article distributed in accordance with the Creative Commons Attribution Non Commercial (CC BY-NC 4.0) license, which permits others to distribute, remix, adapt, build upon this work non-commercially, and license their derivative works on different terms, provided the original work is properly cited, appropriate credit is given, any changes made indicated, and the use is non-commercial. See: http://creativecommons.org/licenses/by-nc/4.0/.

Author note $\mathrm{HG}$ is a medical student at the University of Limerick School of Medicine and a research assistant at the Public Health Master program at the University of Limerick. SRG is a postdoctoral researcher at the Public Health Master program at the University of Limerick. KE is a senior lecturer in public health and the director of the Public Health Master program at the School of Medicine at University of Limerick.

ORCID iD

Khalifa Elmusharaf http://orcid.org/0000-0001-8652-1867

\section{REFERENCES}

1 Frenk J, Hunter DJ, Lapp I. A renewed vision for higher education in public health. Am J Public Health 2015;105:S109-13.

2 CEPH. Accreditation criteria [online], 2016. Available: www.ceph.org [Accessed 1 Dec 2019].

3 PHAC. CORE competencies for public health in Canada release 1.0 [online]. Available: https://www.canada.ca/content/dam/phac-aspc/ documents/services/public-health-practice/skills-online/corecompetencies-public-health-canada/cc-manual-eng090407.pdf [Accessed 1 Dec 2019].

4 Kelly T, Lazenby M. Developing and validating learning domains, competencies, and evaluation items for global health clinical immersion practicums for graduate-level nursing programs. J Adv Nurs 2019;75:234-52.

5 Worley J, Heyland M. Evaluating competency based education modules in an online nurse practitioner course. J Nurs Educ Pract 2019;9.

6 Bogossian FE, Cant RP, Ballard EL, et al. Locating "gold standard" evidence for simulation as a substitute for clinical practice in 
prelicensure health professional education: A systematic review. J Clin Nurs 2019;28:3759-75.

7 Bennett CJ, Walston SL. Improving the use of competencies in public health education. Am J Public Health 2015;105:S65-7.

8 Steigerwald D, Nolan C, Loux T, et al. Improving public health competencies through required practice experience. Public Health 2016;140:265-7.

9 Ramaswamy R, Mosnier J, Reed K, et al. Building capacity for public health 3.0: introducing implementation science into an mph curriculum. Implementation Sci 2019;14.

10 Hernandez KE, Bejarano S, Reyes FJ, et al. Experience preferred: insights from our newest public health professionals on how internships/practicums promote career development. Health Promot Pract 2014;15:95-9.

11 Sullivan LM, Velez A, Edouard VM. Realigning the master of public health (MPH) to meet the evolving needs of the workforce. Perspect Pedagog 2017.

12 Arksey H, O'Malley L. Scoping studies: towards a methodological framework. Int J Soc Res Methodol 2005;8:19-32.

13 Levac D, Colquhoun H, O'Brien KK. Scoping studies: advancing the methodology. Implement Sci 2010;5:69.

14 Adams J, Hillier-Brown FC, Moore HJ, et al. Searching and synthesising 'grey literature' and 'grey information' in public health: critical reflections on three case studies. Syst Rev 2016;5:164.

15 Paez A. Gray literature: an important resource in systematic reviews. $J$ Evid Based Med 2017;10:233-40.

16 Peters MDJ, Godfrey CM, Khalil H, et al. Guidance for conducting systematic scoping reviews. Int J Evid Based Healthc 2015;13:141-6.

17 Villanueva AM, Hovinga ME, Cass JL. Master of public health community-based Practicum. J Public Heal Manag Pract 2011:17:337-43.
18 Boelen C. Coordinating medical education and health care systems: the power of the social accountability approach. Med Educ 2018;52:96-102.

19 Global consensus for social accountability of medical schools [online]. Available: https://healthsocialaccountability.org/ [Accessed 23 Mar 2019].

20 Goodman J. Virtual practicums within an MPH program: a career development case study. Health Promot Pract 2015;16:7-11.

21 Brambleby P, Coates R. Learning contracts in higher professional training: a user's guide. Postgrad Med J 1997;73:279-82.

22 Harden RM. Developments in outcome-based education. Med Teach 2002;24:117-20.

23 APHEA - core curriculum areas [online]. Available: https://www. aphea.be/Pages/A2.CURRICULA/Curriculum_core_areas.html [Accessed 7 Mar 2019].

24 Calhoun JG, Ramiah K, Weist EM, et al. Development of a core competency model for the master of public health degree. $\mathrm{Am} J$ Public Health 2008;98:1598-607.

25 Schuster W, Stevens KB. Supervising Practicum students. Teacher Education and Special Education 1991;14:169-76.

26 Beck C, Kosnik C. Professors and the Practicum. J Teach Educ 2002;53:6-19.

27 Carraccio C, Englander R, Holmboe ES, et al. Driving care quality: aligning trainee assessment and supervision through practical application of entrustable professional activities, competencies, and milestones. Acad Med 2016;91:199-203.

28 Landmark BT, Hansen GS, Bjones I, et al. Clinical supervision factors defined by nurses as influential upon the development of competence and skills in supervision. J Clin Nurs 2003;12:834-41.

29 Cashman SB, Seifer SD. Service-learning: an integral part of undergraduate public health. Am J Prev Med 2008;35:273-8. 